\title{
Arboviral infections: the importance of obtaining greater attention on the severe threat in the maternal and the concept's health
}

\begin{abstract}
Arboviral infections, especially Dengue, Chikungunya and Zika have been composed of a severe and growing global threat in the populations' health. ${ }^{1}$ The co-circulation of the four Dengue virus serotypes and the two most recently introduced virus in Brazil, Chikungunya and Zika (2015-2016), and in other countries in the Americas, these viruses have caused a dramatic increase such as, the number of the cases, complications and deaths in the region. Recently, the introduction of the Zika virus in Brazil has brought an unprecedented number of microcephaly cases attributed to the congenital virus infection, particularly in the Northeast region. 2

In the world, it is estimated that $90 \%$ of the pregnancies which occur annually in endemic areas of arboviruses, about $10 \%$ are exposed to the infection. ${ }^{3}$ Most of the Arboviral infections are asymptomatic or manifest as acute infectious of lesser severity, whose initial symptoms are usually, fever, headache, myalgia, arthralgia and maculopapular rash, these are non-specific and similar among each other.4,5 In pregnant women, although the manifestations are usually indistinguishable from the rest of the population, the risk of progression in the severe forms of the disease are shock and hemorrhagic syndromes, which are the highest, according to studies. ${ }^{3}$ Similarly, Arboviral infection in pregnant women increases the risk of pregnancy complications, such as, preterm labor, preterm placental abruption, preeclampsia, vaginal bleeding and maternal death, which may also affect the concept's health by transmitting of the virus via the placenta or during childbirth. However, despite the potential risk of arboviruses in pregnant woman and her fetus' health, this draws attention to the scarcity or near-absence of the detailed clinical data enabling early detection of complications that may arise during the pregnancy. In addition, preventive and therapeutic measures aimed for these diseases are not available yet.

In areas with intensive circulation of Arboviruses, like in most Brazilian urban centers, the high proportion of women are exposed to such infections during the pregnancy, especially in periods of seasonal peak, are as shown in other previous studies.6,7 Considering that the high frequency of acute asymptomatic infections, or if they present uncharacteristic symptoms and signs, and the apparent specificity of obstetric complications associated to Arbovirus infections, the diagnostic confirmation of these cases becomes a challenge. Thus, it is plausible to assume that in areas of intense circulation of Arbovirus, knowing that much of the complications arising from this cause are not being identified in the health services and so, consequently, they are being inadequately treated and underreported.

Currently, in Latin American countries, there are a number of ongoing research, Nationally and multicentric, to estimate the percentage of symptomatic and asymptomatic infections and to investigate the obstetric outcomes of Arboviruses, especially Zika, in the gestational period; and to determine the rate of malformations and other adverse outcomes of the infected fetuses. ${ }^{8}$ Such studies certainly will bring important contributions to obtain better knowledge of this problem. However, it becomes essential and urgent to conduct more clinical and epidemiological research in a large scale for the best clinical and laboratory characterization in these cases, developing algorithms diagnoses for early detection, adequate management and prevention on deaths. It is also important to develop studies to know the magnitude and impact of such maternal and neonatal complications in the health services, aiming to organize services to care for the cases and to qualify health professionals in the area.
\end{abstract}


At the same time, it is relevant, that Journals with scopus are linked to pregnant woman and her child's health, as the Brazilian Journal of Mother and Child's Health and others, are the sources of a wide dissemination of knowledge in the health area. The dissemination of such knowledge provided through scientific articles of quality is certainly, part of a struggle in coping to such medical problems.

\section{References}

1. Hotez PJ, Murray KO. Dengue, West Nile virus, chikungunya, Zika - and now Mayaro? PLOS Neg1 Trop Dis. 2017; 11(8): $\mathrm{e} 0005462$.

2. Paixão ES, TeixeiraMG, RodriguesLC. Zika, chikungunya and dengue: the causes and threats of new and re-emerging arboviral diseases. BMJ Global Health. 2017; 3 (Suppl 1): e000530.

3. Charlier C, Beaudoin Marie-Claude, Couderc T, Lortholary O, Lecuit M. Arboviruses and pregnancy: maternal, fetal, and neonatal effects. Lancet Child Adolesc Health. 2017; 1 (2): 134-46.

4. ZannoliS, MorottiM, Denicolò A, Tassinari M, Chiesa C, Pierro A, Sambri V. Global epidemiology of Zika and Chikungunya virus human infections. Microbiologia Medica. 2017; 32 (3): 82-96.

5. Patterson J, sammon M, Garg M. Dengue, Zika e Chikungunya: emerging arboviruses in the new world. West J Emerg Med. 2016; 17 (6): $671-9$.

6. Leite RC, Souza AI, Castanha PM, Cordeiro MT, Martelli CT, Ferreira AL, Katz L, Braga C. Dengue infection in pregnancy and transplacental transfer of anti-dengue antibodies in Northeast, Brazil. J Clin Virol. 2014; 60 (1): 16-21.

7. Araujo TVB, Ximenes RAA, Miranda-Filho DB, Souza WV, Montarroyos UR, Melo APL, Valongueiro S, et al. Association between microcephaly, Zika virus infection, and other risk factors in Brazil: final report of a case-control study. Lancet Infect Dis. 2017; 18 (3): 328 - 36.

8. Albuquerque MFPM, Souza WV, Araújo TVB, Braga MC, Miranda DBF, Ximenes RAA, Melo Filho DA, Brito CAA, Valongueiro S, Melo APL, Brandão-Filho SP, Martelli CMT. Epidemia de microcefalia e vírus Zika: a construção do conhecimento em epidemiologia. Cad Saúde Pública. 2018; 34 (P): e00069018.

\section{Maria Cynthia Braga 1 \\ iD https://orcid.org/0000-0002-7862-6455 \\ José Eulálio Cabral Filho 2 \\ (iD https://orcid.org/0000-0001-9121-9910}

1,2 Instituto de Medicina Integral Prof. Fernando Figueira. Rua dos Coelhos, 300. Boa Vista. Recife, PE, Brasil. CEP: 50.070-902. 